\title{
On the improved stability of the version 7 MIPAS ozone record
}

\author{
Alexandra Laeng ${ }^{1}$, Ellen Eckert ${ }^{1}$, Thomas von Clarmann ${ }^{1}$, Michael Kiefer ${ }^{1}$, Daan Hubert ${ }^{2}$, Gabriele Stiller ${ }^{1}$, \\ Norbert Glatthor $^{1}$, Manuel López-Puertas ${ }^{3}$, Bernd Funke ${ }^{3}$, Udo Grabowski ${ }^{1}$, Johannes Plieninger ${ }^{1}$, Sylvia Kellmann ${ }^{1}$, \\ Andrea Linden ${ }^{1}$, Stefan Lossow ${ }^{1}$, Arne Babenhauserheide ${ }^{1}$, Lucien Froidevaux ${ }^{4}$, and Kaley Walker ${ }^{5}$ \\ ${ }^{1}$ Institut für Meteorologie und Klimaforschung, Karlsruhe Institute of Technology, Karlsruhe, Germany \\ ${ }^{2}$ Belgian Institute for Space Aeronomy (BIRA-IASB), Synergistic exploitation of atmospheric data, Brussels, Belgium \\ ${ }^{3}$ Instituto de Astrofísica de Andalucía-CSIC, Granada, Spain \\ ${ }^{4}$ Jet Propulsion Laboratory, California Institute of Technology, Pasadena, USA \\ ${ }^{5}$ Department of Physics, Toronto, University of Toronto, Canada
}

Correspondence: Alexandra Laeng (alexandra.laeng@kit.edu)

Received: 22 September 2017 - Discussion started: 1 November 2017

Revised: 26 July 2018 - Accepted: 1 August 2018 - Published: 10 August 2018

\begin{abstract}
The Michelson Interferometer for Passive Atmospheric Sounding (MIPAS) was an infrared limb emission spectrometer on the Envisat platform. From 2002 to 2012, it performed pole-to-pole measurements during day and night, producing more than 1000 profiles per day. The European Space Agency (ESA) recently released the new version 7 of Level 1B MIPAS spectra, in which a new set of timedependent correction coefficients for the nonlinearity in the detector response functions was implemented. This change is expected to reduce the long-term drift of the MIPAS Level 2 data. We evaluate the long-term stability of ozone Level 2 data retrieved from MIPAS v7 Level 1B spectra with the IMK/IAA scientific level 2 processor. For this, we compare MIPAS data with ozone measurements from the Microwave Limb Sounder (MLS) instrument on NASA's Aura satellite, ozonesondes and ground-based lidar instruments. The ozonesondes and lidars alone do not allow us to conclude with enough significance that the new version is more stable than the previous one, but a clear improvement in long-term stability is observed in the satellite-data-based drift analysis. The results of ozonesondes, lidars and satellite drift analysis are consistent: all indicate that the drifts of the new version are less negative/more positive nearly everywhere above $15 \mathrm{~km}$. The 10-year MIPAS ozone trends calculated from the old and the new data versions are compared. The new trends are closer to old drift-corrected trends than the old uncorrected trends were. From this, we conclude that the nonlinearity correction performed on Level 1B data is an improvement. These results indicate that MIPAS data are now even
\end{abstract}

more suited for trend studies, alone or as part of a merged data record.

\section{Introduction}

The Michelson Interferometer for Passive Atmospheric Sounding (MIPAS) was an infrared (IR) limb emission spectrometer onboard the Envisat platform. It performed pole-topole measurements during day and night, at altitudes from 6 to $70 \mathrm{~km}$ (up to $170 \mathrm{~km}$ in special observation modes), providing more than 1000 daily profiles of about 30 species, temperature and cloud composition. In 2002-2004, the instrument operated at full spectral resolution, giving rise to the retrieved ozone product with a vertical resolution of about $3.5-6 \mathrm{~km}$; this period of MIPAS operations is referred to as the full-resolution (FR) period. Due to a failure of the instrument's mirror slide in 2004, the operations were suspended during almost a year and were resumed in 2005 with reduced spectral but improved vertical and horizontal resolution. The corresponding period until the loss of communications with the Envisat platform in April 2012 is referred to as the reduced-resolution (RR) period of MIPAS operations.

ESA recently released the new version 7 of Level 1B MIPAS spectra. One of two main improvements of this release is that a full instrument misalignment matrix was implemented in this version, which results in better knowledge of tangent altitudes. This change is of minor relevance to the IMK/IAA data product because tangent altitudes are retrieved from the 
spectra (von Clarmann et al., 2003). Another major improvement is the implementation of a new set of time-dependent correction coefficients for the nonlinearity (NL) in the detector response functions. In the previous version, the correction coefficients were taken from preflight studies and were not time dependent, but the instrument is aging and the detector response function is changing (Eckert et al., 2014). This improvement of the Level 1B spectra is expected to have a major impact on MIPAS Level 2 data, by reducing the instrument drift. The goal of the present paper is to demonstrate this improvement for the MIPAS IMK/IAA ozone dataset. The MIPAS IMK/IAA dataset versions V7H_O3_40 (20022004, for the FR period) and V7R_O3_240 (2005-2012, for the RR period) are part of the new edition of the HARMonized dataset of OZone profiles (HARMOZ) database (Sofieva et al., 2013). They are also used in the Long-term Ozone Trends and Uncertainties in the Stratosphere (LOTUS) Stratosphere-troposphere Processes And their Role in Climate (SPARC) initiative as a parent dataset for two longterm ozone time series: the merged SAGE II-MIPAS-OMPS NASA dataset (Laeng et al., 2018) and the merged SAGE IICCI-OMPS Sask dataset (Sofieva et al., 2017). ${ }^{1}$

\section{MIPAS retrieval with IMK/IAA research processor}

The processing scheme of the MIPAS IMK/IAA research processor, also known as KIT MIPAS processor, and its adjustment to the RR spectra of MIPAS are described in von Clarmann et al. (2003, 2009), respectively. In the retrievals, MIPAS Level 1B spectra are inverted to vertical profiles of atmospheric state parameters. After linearization of the radiative transfer problem and after writing the solution in an interactive context in order to take NL into account, the estimation of state parameters is performed iteratively as following:

$$
\begin{gathered}
\boldsymbol{x}_{i+1}=\boldsymbol{x}_{i}+\left(\mathbf{K}_{i}^{T} \mathbf{S}_{y}^{-1} \mathbf{K}_{i}+\mathbf{R}+\lambda \mathbf{I}\right)^{-1}\left(\mathbf { K } _ { i } ^ { \mathrm { T } } \mathbf { S } _ { y } ^ { - 1 } \left[\boldsymbol{y}_{\text {meas }}-\right.\right. \\
\left.\left.\boldsymbol{y}\left(\boldsymbol{x}_{i}\right)\right]-\mathbf{R}\left(\boldsymbol{x}_{i}-\boldsymbol{x}_{\mathrm{a}}\right)\right) .
\end{gathered}
$$

Here, the following are true.

- $\boldsymbol{x}_{i}$ is the $n_{\max }$-dimensional vector of unknown parameters estimated on the $i$ th iteration.

- $\mathbf{K}_{i}$ is the $m_{\max } \times n_{\max }$ Jacobian, containing the partial derivatives of all $m_{\max }$-simulated measurements $\boldsymbol{y}$ under consideration with respect to all unknown parameters $\boldsymbol{x}$.

- $\mathbf{K}_{i}^{\mathrm{T}}$ denotes the transposed matrix $\mathbf{K}_{i}$.

\footnotetext{
${ }^{1}$ SAGE II: Stratospheric Aerosol and Gas Experiment, CCI: ESA's Climate Change Initiative, OMPS: Ozone Mapping and Profiler Suite, NASA: National Aeronautics and Space Administration.
}

- $\mathbf{S}_{\boldsymbol{y}}$ is the $m_{\max } \times m_{\max }$ covariance matrix of measurement noise.

- $\mathbf{R}$ is the $n_{\max } \times n_{\max }$ regularization matrix.

- $\lambda \mathbf{I}$ is the $n_{\max } \times n_{\max }$ Levenberg-Marquardt term (Levenberg, 1944; Marquardt, 1963).

- $\boldsymbol{y}_{\text {meas }}$ is the $m_{\max }$-dimensional vector of measurements under consideration.

- $\boldsymbol{y}\left(\boldsymbol{x}_{i}\right)$ is the forward-modeled spectrum using parameters $\boldsymbol{x}_{i}$ from the $i$ th iteration step.

$-\boldsymbol{x}_{\mathrm{a}}$ is the related a priori information.

In stratospheric-tropospheric retrievals, local thermodynamic equilibrium (LTE) is assumed (the processor is designed such that the major contributors to the IR spectrum are the first to be retrieved, before the gases with weak spectral features). First, the spectral shift of the spectra is determined. Then, temperatures and altitude pointing information (i.e., the elevation angle of the line of sight of the instrument) are jointly retrieved; the retrieved quantity is referred to as TLOS. Then, traces gas abundances are retrieved. The sequence of these operations in $\mathrm{v} 7$ retrievals is $\mathrm{O}_{3}, \mathrm{H}_{2} \mathrm{O}$, and then the other trace gases. As a general rule, results of preceding steps are used as input for the subsequent retrieval steps, i.e., the $\mathrm{O}_{3}$ retrieval uses retrieved temperatures and pointing information, and the subsequent trace gas retrievals will use retrieved $\mathrm{O}_{3}$ abundances. In addition to each target species, microwindow-dependent continuum radiation profiles and microwindow-dependent, but height-independent, zero-level calibration corrections are jointly fitted.

\subsection{New v7-dedicated ozone retrieval setup}

A new dedicated ozone retrieval setup was recently developed for the IMK/IAA Level 2 processor. The MIPAS ozone profiles produced with this retrieval setup are referred to as data versions V7H_O3_40 and V7R_O3_240. All improvements reported below refer to both the FR and the RR data.

One of the most relevant changes in the improved retrieval setup is not related to the ozone retrieval itself but to the preceding temperature retrieval. The radiative transfer forward calculation now uses information on the horizontal two-dimensional temperature variation along the line of sight from the European Centre for Medium-Range Weather Forecasts (ECMWF) reanalysis. While the temperature at the measurement geolocation is still retrieved from the MIPAS spectra, the horizontal temperature variation is prescribed by the analysis data. This allows a more accurate retrieval in situations in which neither the assumption of local horizontal uniformity nor the approximation of horizontal temperature variation by linear gradients, as described by von Clarmann et al. (2009), is adequate. Typically the old approaches lead to problems when the line of sight of a measurement crosses 

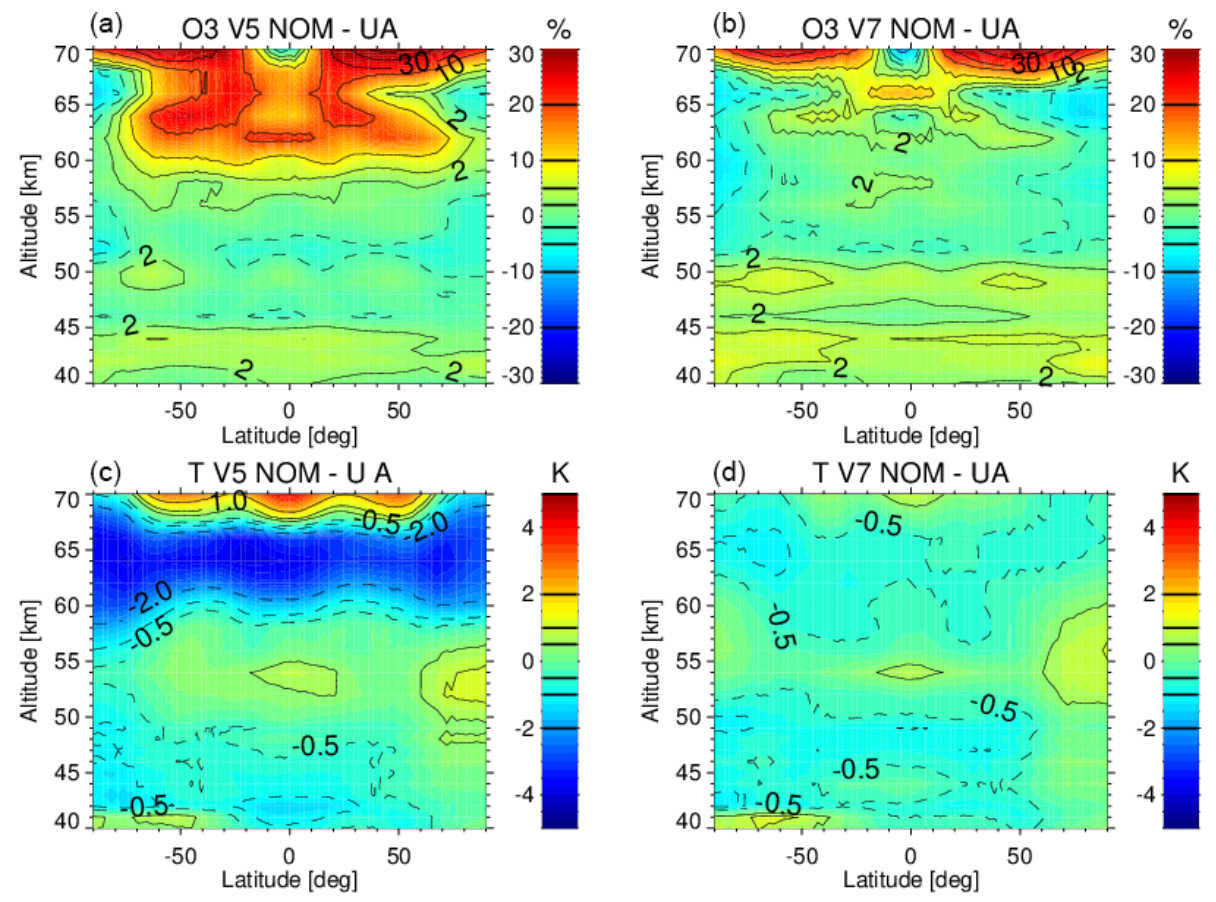

Figure 1. Climatological mean differences of ozone $(\mathbf{a}, \mathbf{b})$ and temperature $(\mathbf{c}, \mathbf{d})$ retrievals from the old $(\mathbf{a}, \mathbf{c})$ and new $(\mathbf{b}, \mathbf{d})$ versions of data from retrievals from MIPAS middle and upper stratospheric modes.

the edge of the polar vortex. We refer to this change as a 2-D field. Above approximately $60 \mathrm{~km}$ there are no ECMWF data available to build the 2-D information. There, a retrieval of a linear horizontal gradient, in addition to the temperature retrieval, is performed. However, the retrieved gradient profile is strongly regularized towards zero below the stratopause. Only above does it serve to include gradient information at altitudes at which these are not given externally. All these changes in the temperature retrieval are referred to as TLOS V7 retrieval.

Above the uppermost tangent altitude, MIPAS cannot measure altitude-resolved temperature profiles because at most 1 degree of freedom is achievable there. Thus, the choice of adequate a priori temperature information is particularly important at these altitudes. In previous data versions, MSIS (Hedin, 1991) temperatures served as a priori values at these altitudes. Particularly in situations of elevated stratopause events, this climatological model did not represent the actual upper stratospheric-lower mesospheric conditions very well, and the related temperature retrieval error was found to propagate noticeably onto the retrieved ozone. Validation results of the previous version were found to be particularly biased during such elevated stratopause events. Thus, in this new version, a priori information on temperature at altitudes above $60 \mathrm{~km}$ is taken from a dedicated temperature climatology based on simulations of the Whole Atmosphere Community Climate Model (WACCM) and MIPAS middle and upper atmospheric mode temperatures from version 5 (García-Comas et al., 2014). The WACCM tempera- ture fields were taken from CCMI-REFC1SD simulations, in specified dynamics mode, sampled at MIPAS locations and times. The WACCM model is described in detail by Marsh (2011) and Marsh et al. (2013), while the implementation of the specified dynamics mode and the most recent changes in the model, including those of the gravity wave parameterization and the Prandtl number, are described in García et al. (2016) and López-Puertas et al. (2017). In the a priori temperature climatology, the WACCM temperature fields have been corrected by using the MIPAS middle and upper atmosphere temperatures (García-Comas et al., 2014). For this, an altitude- and latitude-dependent seasonal correction function has been derived from multi-annual averages of MIPAScollocated WACCM differences. Also, the $\mathrm{CO}_{2}$ mixing ratios used for the temperature retrieval are now based on WACCM simulations.

To evaluate the effect of the new (v7) retrieved temperature on the $\mathrm{v} 7$ nominally retrieved $\mathrm{O}_{3}$, we compared climatological means of temperature and ozone from the old and new MIPAS data versions with MIPAS retrievals from middle and upper atmosphere modes. The latter data were already validated for both temperature (García-Comas et al., 2014) and for $\mathrm{O}_{3}$ (López-Puertas et al., 2018). Figure 1 shows climatological mean differences in ozone (top row) and temperature (bottom row) for version 5 (old) (left column) and version 7 (new) (right column). A close look at the 55-67 km altitude region in Fig. 1 reveals that the use of the new v7 temperatures substantially improves the agreement in the low mesosphere of both temperature and ozone retrieved from MIPAS 

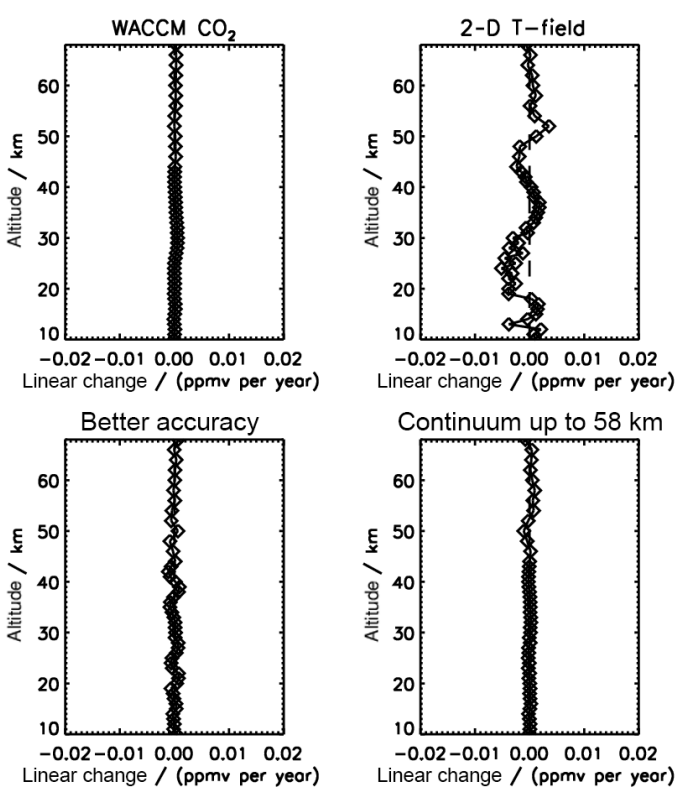
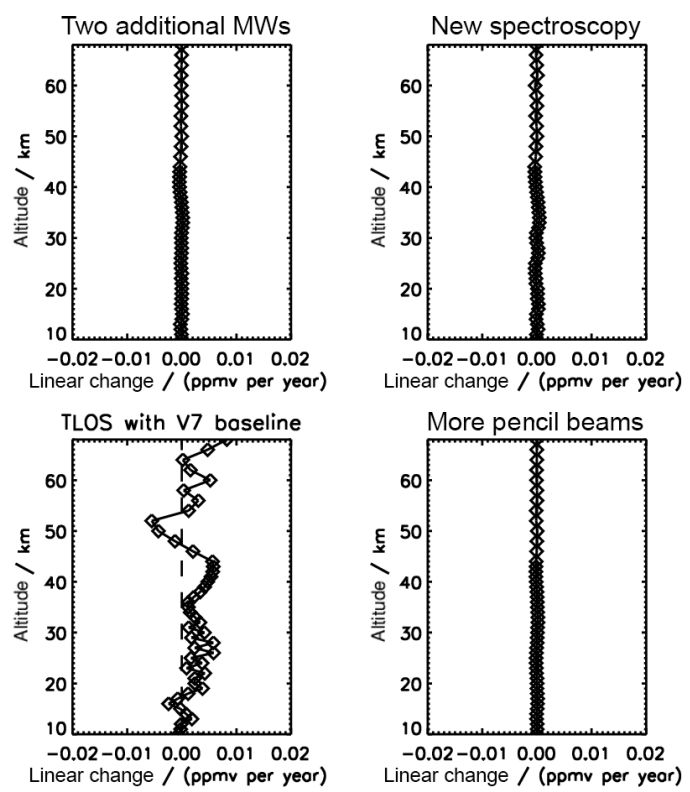

Figure 2. Sensitivity study: how different changes in retrieval setup affect the ozone retrieval. For each change, we show the linear term of differences of ozone retrieved from v7 spectra, using the new retrieval setup and the previous retrieval setup. Each panel corresponds to a retrieval setting for which only one parameter (which is stated in the title of the panel) is changed, and all other parameters remain unchanged.

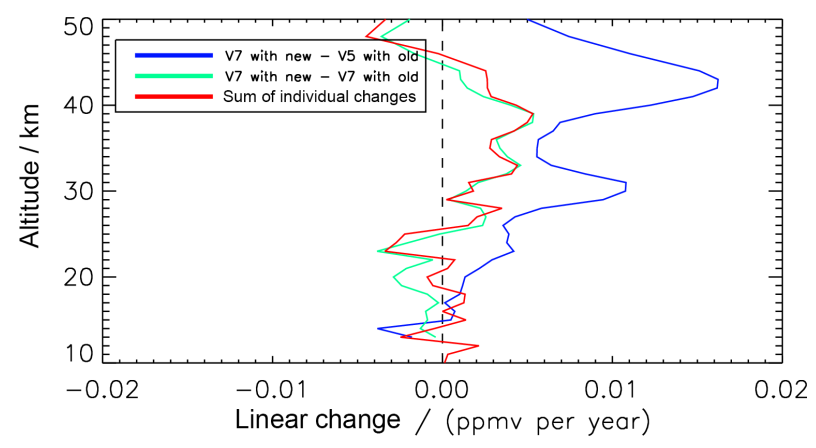

Figure 3. Sensitivity of the linear change in ozone to the changes in retrieval setup and Level 1B spectra. Versions 5 and 7 refer to the versions of Level 1B MIPAS spectra on which the retrieval is run. "Old" and "new" refer to the old and new retrieval setups. The blue line shows the linear change in ozone when both the retrieval setup and the version of the Level 1B spectra are changed. The green line illustrates the linear change in ozone when only the retrieval setup is changed and is applied in both cases to the same version 7 Level 1B spectra. The red line shows the linear change in ozone originating from the sum of individual changes in the retrieval, shown in Fig. 2, applied to the same version of Level 1B spectra.

nominal mode with respect to MIPAS middle and upper atmosphere modes.

Further changes in the $\mathrm{O}_{3}$ retrieval setup refer to the background continuum radiation. Initially, as described in von Clarmann et al. (2003), in retrievals of temperature, ozone and of most subsequent species, the continuum absorption coefficient was fitted up to $32 \mathrm{~km}$ in altitude only. Fitting background continuum radiation was deemed not necessary at upper altitudes because no sizable aerosol contributions were expected above the stratospheric aerosol layer, which extends from the tropopause up to $30 \mathrm{~km}$ in altitude. However, Neely et al. (2011) provided some evidence that, due to meteoric dust, there are relevant aerosol particle abundances above the stratospheric aerosol layer. Background continuum radiation was then fitted up to $48 \mathrm{~km}$ in altitude for the previous versions of ozone retrievals (V5R_O3_224/225) and for some subsequent species. For $\mathrm{SF}_{6}$ (continuum fitted up to $49 \mathrm{~km}$ ) and $\mathrm{CH}_{4}$ and $\mathrm{N}_{2} \mathrm{O}$ (continuum fitted up to $58 \mathrm{~km}$ ) retrievals, this approach removed some retrieval artifacts (Haenel et al., 2015; Plieninger et al., 2015). In order to homogenize the retrievals of different species, in the present version, both temperature and ozone retrievals contain background radiation fitted up to $58 \mathrm{~km}$ in altitude. In the new retrieval settings, $\mathrm{H}_{2} \mathrm{O}$ mixing ratios are treated as a joint fit variable in the ozone retrieval. For this purpose two additional $\mathrm{H}_{2} \mathrm{O}$ microwindows have been included in the ozone retrieval and $\mathrm{H}_{2} \mathrm{O}$ is jointly fitted with ozone. This provides a better constraint of $\mathrm{H}_{2} \mathrm{O}$ in the upper troposphere and lower stratosphere (UTLS).

Beyond this, the forward model KOPRA (Stiller, 2000) is now run with higher numerical accuracy. The change consists in a somewhat smaller wave number interval for calculation of the absorption coefficients (from 0.00125 to $0.009765625 \mathrm{~cm}^{-1}$ ) and in an extended width (up to a decrease to $0.1 \%$ of center value) of the applied apodization function. In the retrieval of TLOS, preceding the retrieval of ozone, now five pencil beams are used for the numer- 
ical integration of radiances over the instrument fields of view for all tangent altitudes. While the same $\mathrm{O}_{3}$ spectroscopic data were used as with preceding data versions, spectroscopic data of some interfering species were updated; e.g., $\mathrm{CO}_{2}$ spectroscopy was updated from MIPAS pf3.0 (Flaud et al., 2003) to HITRAN-2012; $\mathrm{N}_{2} \mathrm{O}$ spectroscopy was updated from HITRAN-2000 to HITRAN-2008; $\mathrm{CH}_{4}$ spectroscopy was updated from the 2002 update of HITRAN2000 to HITRAN-2008; carbonyl sulfide spectroscopy was updated from the 2006 update of HITRAN-2004 to the 2009 update of HITRAN-2008.

The effect of changes in the retrieval setup, summarized above, on the linear change in ozone were analyzed in the following way. The retrieval was applied to the v7 MIPAS spectra first with the old setup. Changes described above were then applied one by one, while all other changes were deactivated. For each change, differences in ozone retrieved with the old setup and with the setup modified by one parameter only were calculated for a set of orbits over the MIPAS RR period; then the linear term of differences was extracted, in parts per million by volume per year. Results of this sensitivity study are presented in Fig. 2. As expected, two major impacts on ozone come from the way the temperature is retrieved in a preceding step. The sum of all individual changes is plotted as a red curve in Fig. 3. The difference between the estimated linear change in ozone with a retrieval setup in which all individual changes are applied simultaneously and the linear change estimated with the old setup, both applied to the same new MIPAS version 7 spectra is plotted as the green curve in Fig. 3. As expected, it is very close to the sum of individual changes in the retrieval setup (red curve). The total linear change in ozone retrieval (new spectra and new retrieval setup) is plotted as the blue curve in Fig. 3. As expected, the major cause of the total linear change of retrieved ozone is the use of the new version of MIPAS spectra; it can be visualized as the difference between the blue and the green curves in Fig. 3.

\subsection{Diagnostics}

IMK-IAA MIPAS results are characterized by error estimates, as well as vertical and horizontal averaging kernels. The last two are used to estimate the spatial resolution of the retrievals. The gain function is calculated as follows: $\mathbf{G}=\left(\mathbf{K}^{T} \mathbf{S}_{y}^{-1} \mathbf{K}+\mathbf{R}\right)^{-1} \mathbf{K}^{T} \mathbf{S}_{y}^{-1}$. The covariance matrices of the state vector and of the measurement are linked by $\mathbf{S}_{x}=\mathbf{G} \mathbf{S}_{y} \mathbf{G}^{\mathrm{T}}$. The averaging kernel matrix, reflecting the sensitivity of the retrieved profile to the change of state parameters, is $\mathbf{A}=\mathbf{G K}$. The random error covariance matrix $\mathbf{S}_{\text {random }}$ of the retrieved quantity $x$ is calculated as $\mathbf{S}_{\text {random }}=\left(\mathbf{K}^{\mathrm{T}} \mathbf{S}_{\boldsymbol{y}}^{-1} \mathbf{K}+\mathbf{R}\right)^{-1} \mathbf{K}^{\mathrm{T}} \mathbf{S}_{\boldsymbol{y}}^{-1} \mathbf{K}\left(\mathbf{K}^{\mathrm{T}} \mathbf{S}_{\boldsymbol{y}}^{-1} \mathbf{K}+\mathbf{R}\right)^{-1}$ and the linear mapping $\Delta \boldsymbol{x}_{j}$ of the uncertainty $\Delta b_{j}$ of parameter $b_{j}$ is $\Delta \boldsymbol{x}_{j}=\left(\mathbf{K}^{T} \mathbf{S}_{y}^{-1} \mathbf{K}+\mathbf{R}\right)^{-1} \mathbf{K}^{T} \mathbf{S}_{y}^{-1} \times$ $\left[\boldsymbol{y}\left(\boldsymbol{x}, b_{j}+\Delta b_{j}\right)-\boldsymbol{y}\left(\boldsymbol{x}, b_{j}\right)\right]$. The covariance matrices are

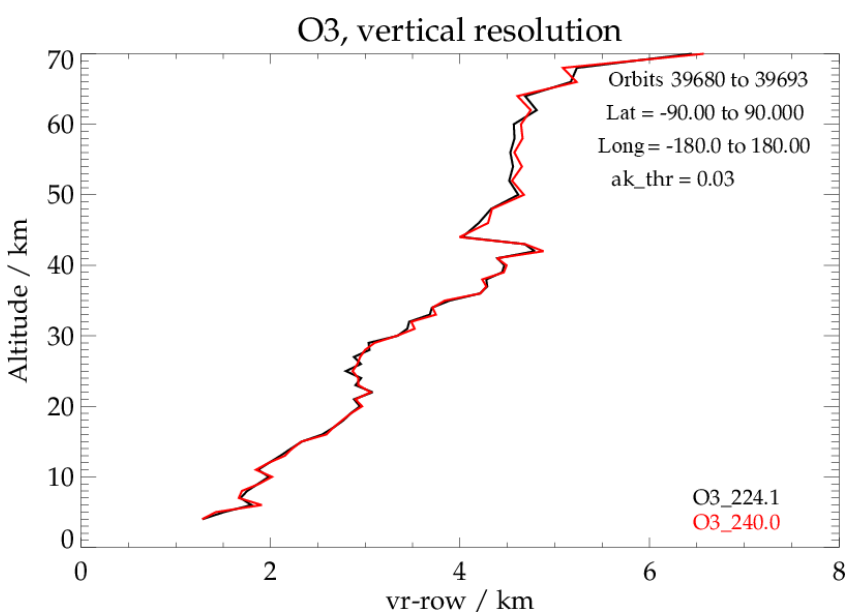

Figure 4. Vertical resolution of ozone profiles from v5 and v7, derived from the full-width at half maximum (FWHM) of rows of the averaging kernel matrix.

stored for all retrieved profiles and are available on demand. Two additional criteria are usually applied to the retrieved data in order to evaluate the quality of the profile: (1) results for which the diagonal value of the averaging kernel is less (in absolute value) than 0.03 are considered mistrustful; (2) results related to parts of the atmosphere not sensed by MIPAS (i.e., below the lowermost used tangent altitude) are considered mistrustful. There is no substantial change in averaging kernels of retrieved ozone profiles between version 5 and version 7 . The vertical resolution is determined by the vertical sampling of the instrument, which in the case of MIPAS RR measurements, varied from 1.5 to $4 \mathrm{~km}$, and regularization. The vertical resolution varies between 2.5 and $4 \mathrm{~km}$ at $10-40 \mathrm{~km}$ altitude and between 4 and $6 \mathrm{~km}$ at $40 \mathrm{~km}$ and higher. The vertical resolution derived from the full-width at half maximum (FWHM) of rows of the averaging kernel matrix for the old and the new versions is shown in Fig. 4: it varies between 2 and $3 \mathrm{~km}$ in the troposphere, varies between 3 and $5 \mathrm{~km}$ in the stratosphere, and goes up to $5 \mathrm{~km}$ at $50-65 \mathrm{~km}$ altitudes. The vertical resolution did not change substantially between the two versions.

\subsection{Sanity check of the output of the new processing scheme}

In this section we check whether the new processing scheme and new MIPAS Level 1B spectra introduced artificial biases in the resulting ozone profiles. For this, we compare the MIPAS ozone profiles from the new and the old versions with ozone profiles measured by ozonesondes launched from two ground stations and ozone profiles measured by two satellite instruments. The two MIPAS datasets from the FR and RR periods must be treated as independent datasets because of differences in the processing setups and different vertical resolutions coming from different tangent altitude patterns. 


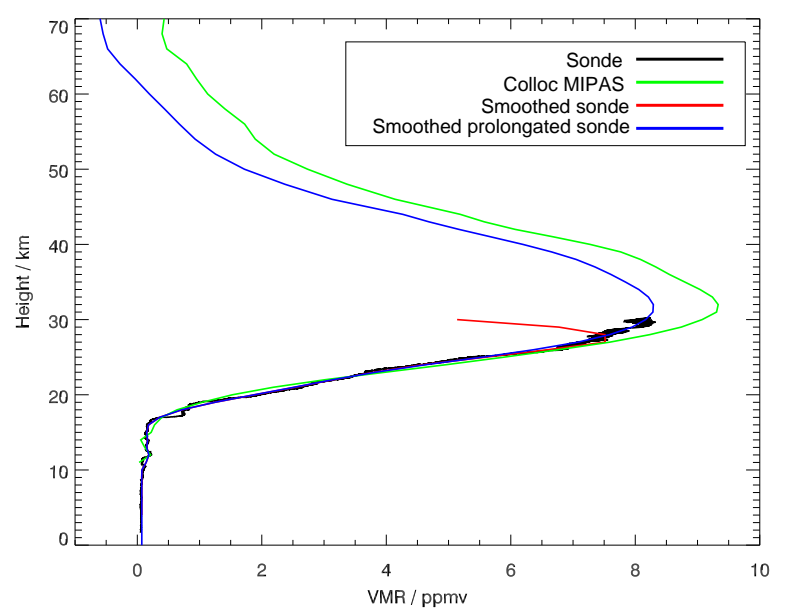

Figure 5. Application of MIPAS AK to the ozonesonde profiles: original ozonesonde profile, collocated MIPAS profile at geolocation 20100630T164035Z, and interpolated, smoothed and prolongated ozonesonde profiles .

We work with two versions of the MIPAS RR (2005-2012) ozone data measured in the instrument nominal mode: version V5R_O3_224/225, which we refer to as "the old version", and version V7R_O3_240, which we refer to as "the new version". The old version was validated in Laeng et al. (2014). This section does not aim to be a full validation of the new version; the latter was performed in the framework of the ESA Ozone_cci project and will be presented in the upcoming paper (Hubert et al., 2018).

The ozone profiles from the two versions were compared to ozonesonde profiles launched from two stations: midlatitudinal Boulder at $39.99^{\circ} \mathrm{N}$ and subtropical Hilo at $19.72^{\circ} \mathrm{N}$. A more extensive ground-based comparison of V7R_O3_240 will be presented in the upcoming paper of Hubert et al. (2018). We have chosen the collocation criteria of $1000 \mathrm{~km}$ and $24 \mathrm{~h}$, which gave rise to 1184 collocated profiles for the Boulder station and 1188 collocated profiles for the Hilo station. In order to take into account the differences in vertical resolutions between ozonesondes and MIPAS profiles, the ozonesonde profiles were smoothed with the MIPAS averaging kernels. When applying the averaging kernels to ozonesonde profiles, the boundary effects are important. To reduce this, each ozonesonde profile was extended at heights over $30 \mathrm{~km}$ by a shifted collocated profile from MIPAS; see Fig. 5.

The results of this intercomparison are shown in Fig. 6 . The percentage relative bias with respect to the reference instrument REF, $100 \times($ MIPAS-REF)/REF of the old MIPAS version is shown in pink, and the new version in green. The results from both stations look fairly consistent, indicating an agreement within $\pm 5 \%$ at $20-30 \mathrm{~km}$ in height, with the new version having a slightly larger (up to $1 \%$ ) bias with respect to ozonesonde profiles compared to the old version in
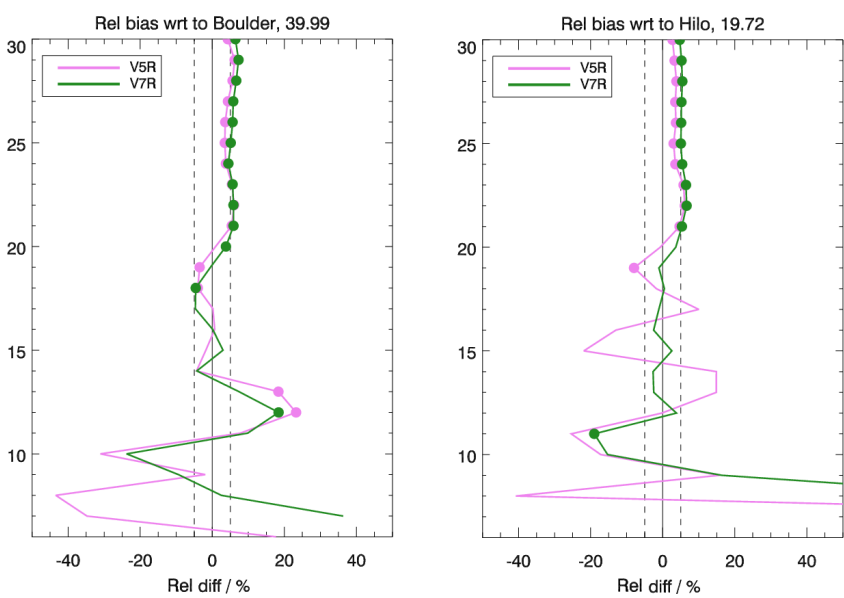

Figure 6. Biases with respect to Boulder $\left(39.99^{\circ} \mathrm{N}\right)$ and Hilo $\left(19.72^{\circ} \mathrm{N}\right)$ ozonesondes for the old (V5R) and new (V7R) MIPAS data versions. The altitudes at which the bias is significant at the $2 \sigma$ level are highlighted by circles.

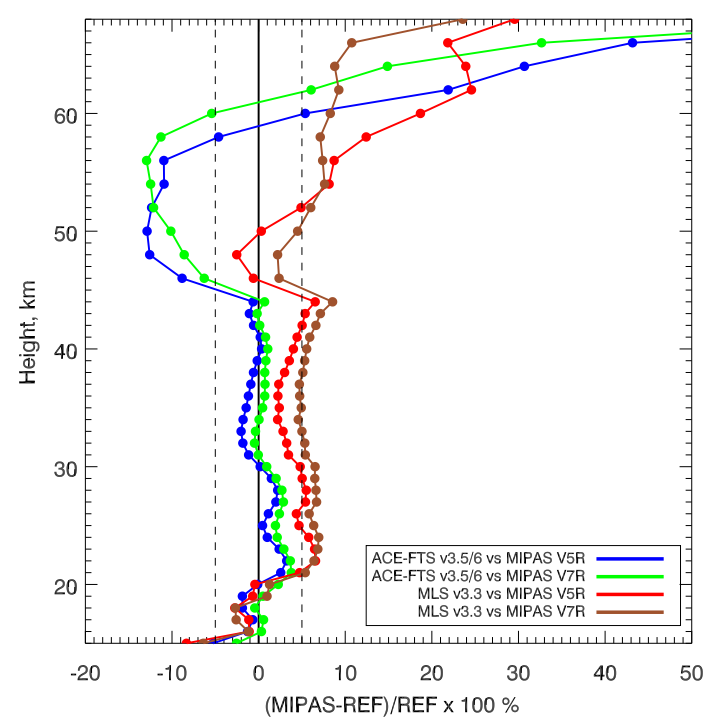

Figure 7. Bias between old and new versions of MIPAS ozone data and the ACE-FTS and MLS profiles. The altitudes at which the bias is significant at the $2 \sigma$ level are highlighted by circles. The averages over the whole globe are presented.

this height range. A clear improvement can be observed at $12-14 \mathrm{~km}$, with the bias reduced by $5 \%$ for Boulder and by up to $10 \%$ reduction at Hilo. Moreover, for the Hilo station, a bias reduction from $15 \%$ to $5 \%$ from 12 to $20 \mathrm{~km}$ can be observed. All these biases are significant at the $2 \sigma$ level.

To assess the bias of the new MIPAS dataset with respect to satellite reference retrievals, the previous version and the new version of MIPAS are compared to the ACE-FTS and MLS datasets. For consistency, both the old and the new versions were compared to the same version of reference instruments, version 3.5/3.6 of ACE-FTS and version 3.3 of MLS. 

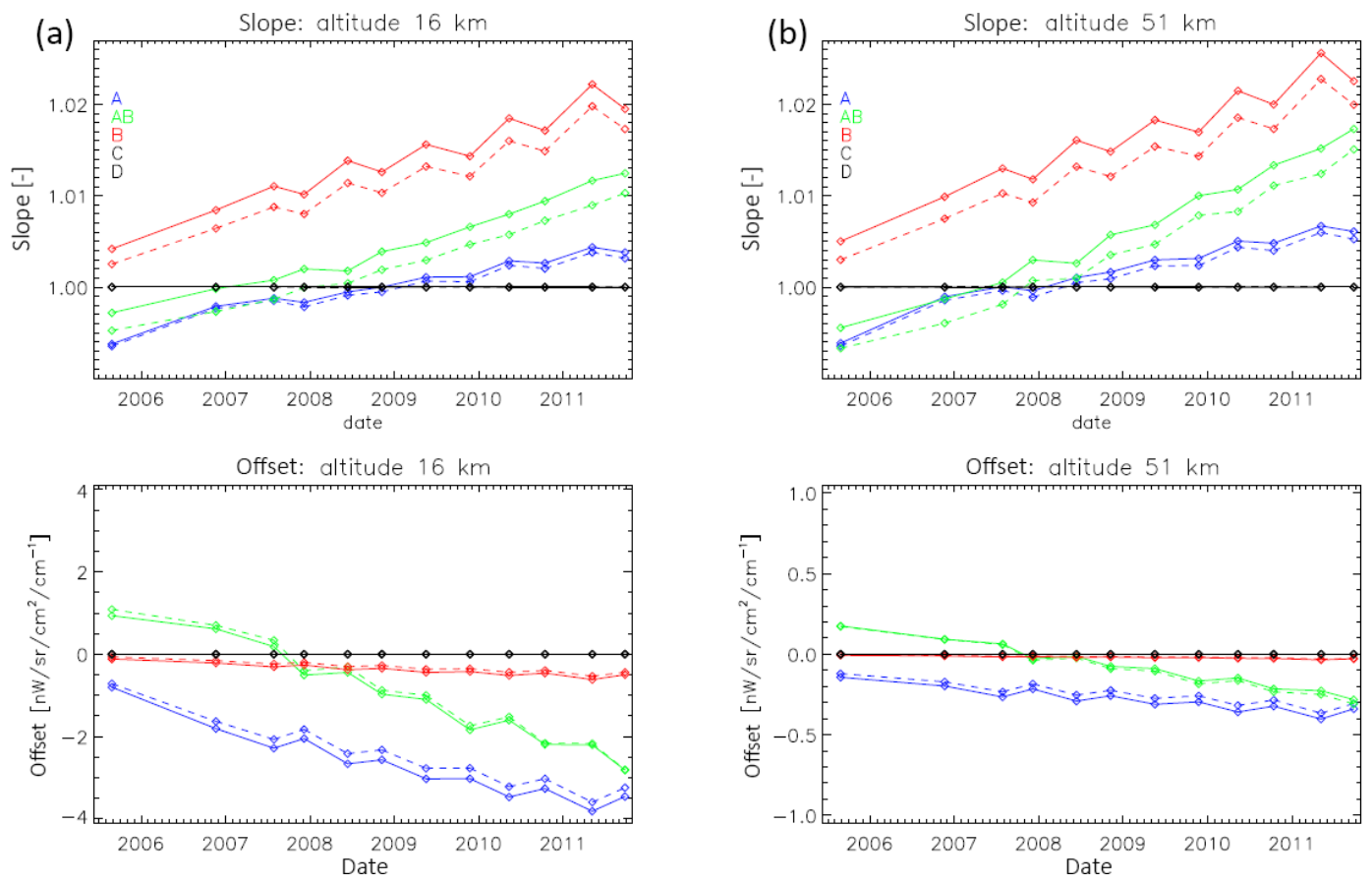

Figure 8. Slope and offset of the linear fit of MIPAS RR Level 1B spectra with the old set of NL coefficient versus spectra with the new set of NL coefficients at $16 \mathrm{~km}$ (a) and $51 \mathrm{~km}$ (b). Solid lines correspond to forward mirror movement, and dashed lines correspond to reverse mirror movement.

Version 3.3 of MLS data was used instead of the most recent version 4.2 in order to keep consistency with the analysis of Eckert et al. (2014). To avoid any sampling effects, comparisons used exactly the same coincidences between the reference dataset and the old and new MIPAS data. The coincidence criteria were chosen to be $500 \mathrm{~km}$ and $5 \mathrm{~h}$ for ACE-FTS and $250 \mathrm{~km}$ and $4 \mathrm{~h}$ for MLS. This gave rise to $\sim 345000$ matched pairs for each version of MIPAS with MLS and 8300 matched pairs for ACE-FTS. Also here, we applied the averaging kernels of MIPAS to both satellite reference datasets; the effect of this operation is, however, negligible due to the small contrast in vertical resolutions of the three datasets. Figure 7 shows the results of these comparisons. The error bars show the standard deviation of corresponding differences. We do not show the standard errors of the means because, due to large sample sizes, the values of standard errors of the means are too small in this case and are not visible in the figure. We choose to present the global average; zonal averages were compared as well (not shown here); no latitudinal biases were canceled out when using the global average. With respect to ACE-FTS, the new version of the MIPAS ozone dataset results in a reduction of the bias by about $2 \%$ at $10-20 \mathrm{~km}, 1 \%$ to $4 \%$ at $30-52 \mathrm{~km}$ and by about $6 \%-8 \%$ at $60 \mathrm{~km}$ and higher. With respect to MLS, a reduction of the bias by $1 \%$ to $12 \%$ can be observed in the lower mesosphere (52 km and higher), while at other heights the bias is slightly increased by $1 \%$ to $4 \%$. Historically, around the ozone volume mixing ratio peak, MIPAS ozone measurements tended to have a high bias (Laeng et al., 2015), which is attributed to the use of the microwindows in the MIPAS AB spectral band $\left(1020-1170 \mathrm{~cm}^{-1}\right)$ at these heights (Glatthor et al., 2018). In this height region, around $35 \mathrm{~km}$, the new version demonstrates an improvement with respect to ACE-FTS for which the bias is reduced from $2 \%$ to almost $0 \%$. With respect to MLS, the bias has increased slightly from $3 \%$ for the previous version to $5 \%$ for the new version. In the UTLS, the comparison with ACE-FTS still demonstrates a clear improvement, and MLS compares better with the new version at $10-12$ and $14-16 \mathrm{~km}$.

From ozonesonde and satellite comparisons described above, we conclude that no artificial biases were introduced either by the new IMK/IAA MIPAS processing scheme or by the new version of MIPAS Level 1B spectra. This conclusion is consistent with findings of the validation activities within the ESA Ozone_cci project (Hubert et al., 2018).

\section{Drift estimation}

\subsection{Level 1B analysis: improvement in the detector NL characterization}

The MIPAS instrument recorded interferograms in the five spectral bands, A: 685-970, AB: 1020-1170, B: 1215-1500, C: $1570-1750$ and D: $1820-2410 \mathrm{~cm}^{-1}$, using eight IR detectors called A1/A2, B1/B2, C1/C2 and D1/D2. The spectral signal in each spectral band is composed of the combined in- 


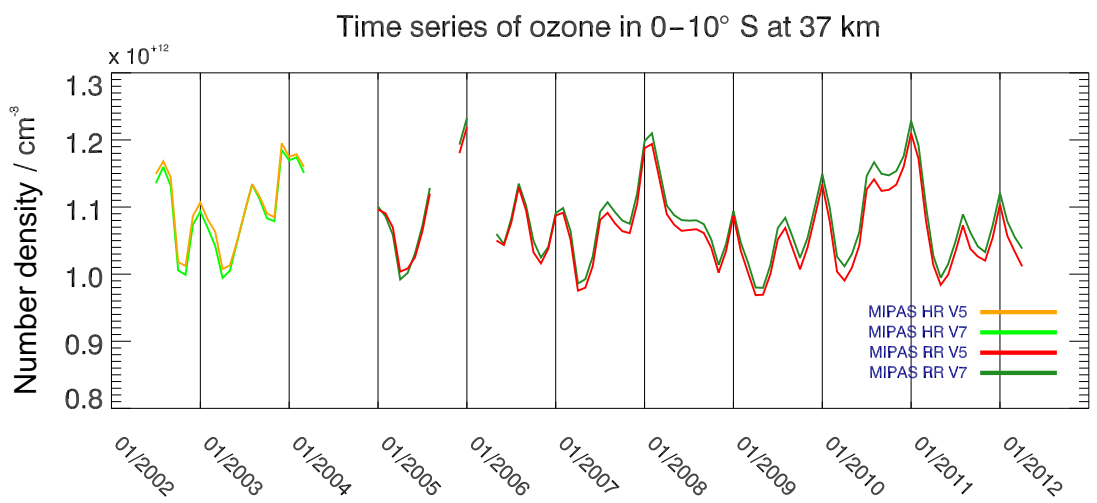

Figure 9. MIPAS time series in the $0-10^{\circ} \mathrm{S}$ latitude band at $37 \mathrm{~km}$. Drift has an approximately linear structure, which is indirect evidence that the methods of estimating MIPAS drift, chosen in Eckert et al. (2014), are appropriate.

formation from the different detectors as follows: the A1/A2 detectors contribute to the MIPAS spectral band A, B1 to $\mathrm{AB}, \mathrm{B} 2$ to $\mathrm{B}, \mathrm{C} 1 / \mathrm{C} 2$ to $\mathrm{C}$ and $\mathrm{D} 1 / \mathrm{D} 2$ to $\mathrm{D}$. Four detectors, namely $\mathrm{A} 1 / \mathrm{A} 2$ and $\mathrm{B} 1 / \mathrm{B} 2$, show a nonlinear response to photon flux, which has to be corrected to obtain the appropriate interferogram. The detectors exhibited aging; essentially the sensitivity degraded slowly over time and the response became more linear. Hence, for the spectral bands A, AB and $\mathrm{B}$, precisely those relevant for the temperature and ozone retrieval, an impact of the detector aging on the measurements has to be expected. There was just one preflight characterization measurement for the detector NL. This characterization was used for in-flight gain calibration throughout the mission (2002-2012) to correct for NL in detector responses up to version 5 of Level 1B MIPAS data. This deficient radiometric calibration caused a drift of the instrument (Kleinert et al., 2007; Kiefer et al., 2013; Eckert et al., 2014), making MIPAS data not suitable for trend studies without preliminary drift removal. (Wagner and Birk, 2005) proposed a new method to characterize the detector NL in-flight measurements in raw data mode. This correction was incorporated in version 7 of MIPAS Level 1B spectra. Plotting MIPAS Level 1B spectra with new NL coefficients (NLCs) against spectra with old NLCs allows us to fit two regression parameters: slope and offset, with ideal values to be close, respectively, to 1 and 0 . These slopes and offsets, for both directions of the interferometer mirror movement, forward and backward, are shown in Fig. 8 for altitudes of $16 \mathrm{~km}$ (Fig. 8a) and 51 km (Fig. 8b).

Figure 8 demonstrates that for Level 1b MIPAS spectra in bands $\mathrm{A}, \mathrm{AB}$ and $\mathrm{B}$, both slope and offset change over time; i.e., the spectra with the old NLCs and the new NLCs slowly drift apart (up to $2 \%$ ). This is the reason why an improvement in long-term stability of MIPAS Level 2 data is expected.

\subsection{Level 2 analysis}

In our definition, drifts are long-term variations in the bias between two instruments. The drifts appear as artificial trends in a signal due to imperfect instrument stability. To assess the long-term stability of the MIPAS ozone dataset, we compared it to a network of data including ozonesondes and ground-based lidars using the method from Hubert et al. (2016) and with Aura MLS (Froidevaux et al., 2008), using the method described by Eckert et al. (2014). As a first rough estimation, we examine the time series of old and new versions of MIPAS ozone data at $37 \mathrm{~km}$ in altitude in the $0-10^{\circ} \mathrm{S}$ latitude band; see Fig. 9. The choice of the latitude band and altitude for such an illustration are driven by the drift estimation from Eckert et al. (2014); see also Fig. 11a: it corresponds to a pixel with strong significant negative drift. The red and the dark green curves in Fig. 9 show the time series of the old and the new MIPAS RR data, respectively. A negative drift of the old data with respect to the new data is clearly seen and is approximately linear. This provides indirect evidence that the methods of estimating the drift of MIPAS, chosen in Hubert et al. (2016) and Eckert et al. (2014), are appropriate.

\subsubsection{Drift with respect to ground-based instruments}

We calculated the network-averaged drift of the old and new MIPAS data versions versus co-located lidar and ozonesonde ozone profiles using the regression and averaging procedure described in Hubert et al. (2016). The ground-based ozonesonde and lidar networks provide, at numerous sites around the world, vertical ozone profiles that - together - cover regions of the troposphere and stratosphere. The sonde data were taken from the archives of the World Ozone and Ultraviolet Radiation Data Centre (WOUDC, http://www.woudc.org, last access: 8 August 2018), the Network for the Detection of Atmospheric Composition Change (NDACC, http://www.ndacc.org, last access: 8 August 2018, Kurylo and Zander, 2001; Lambert et al., 1999) and the Southern Hemisphere ADditional OZonesondes (SHADOZ, http://croc.gsfc.nasa.gov/shadoz, last access: 8 August 2018, Thompson et al., 2012). The lidar data were taken from the NDACC archive (http://www.ndacc.org, last access: 8 

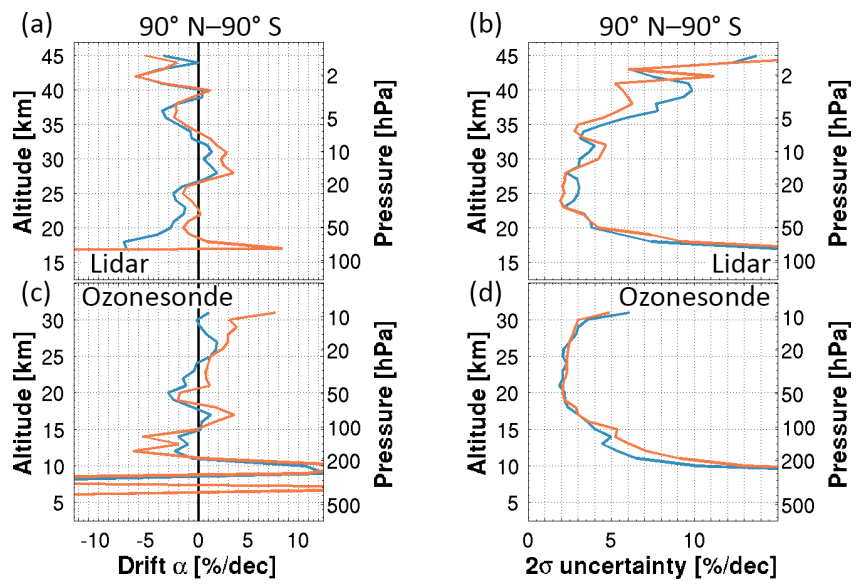

Figure 10. (a, c) Network-averaged drift of the old (blue) and the new (orange) MIPAS ozone versus lidar $(\mathbf{a}, \mathbf{b})$ and ozonesonde (c, d) measurements for 2005-2012 period profiles. (b, d) $2 \sigma$ uncertainty of estimated drifts.

August 2018). The MIPAS profiles were compared to any ground-based measurements that co-locate within $6 \mathrm{~h}$ and $500 \mathrm{~km}$. The latter were smoothed to the vertical resolution of MIPAS and regridded to its native vertical grid. The bias of MIPAS (as a percentage) is estimated as the median value of the relative difference time series $\Delta x_{j}\left(t_{i}, l\right)=$ $100 \times \frac{x_{j, \text { sat }}\left(t_{i}, l\right)-x_{j, \text { gnd }}\left(t_{i}, l\right)}{x_{j, \text { gnd }}\left(t_{i}, l\right)}$, where $x_{j, \text { sat }}(i, l)$ and $x_{j, \text { gnd }}(i, l)$ represent, respectively, satellite and smoothed and regridded ground-based ozone at grid level $l$ of co-located profile pair $i$ at time $t_{i}$ and station $j$. The choice by Hubert et al. (2016) to work in relative units was mainly made to divide out any multiplicative time dependence (e.g., seasonal cycle). This makes the difference values sensitive to low ozone concentrations (e.g., in the UTLS). The analysis of the long-term stability of MIPAS data is performed in two steps. First, the linear drift is estimated at each ground station and vertical level, using an iterative Tukey bisquare reweighted least-squares procedure to fit the relative difference time series to a linear regression model $\Delta x_{j}(t, l)=\alpha_{j}(l)\left(t-t_{0}\right)+\beta_{j}(l)+e_{j}(t, l)$. In a second step, these drift estimates are averaged over a number of ground stations to obtain the network-averaged drift of MIPAS (in percent per decade; see Hubert et al., 2016, for more details). The averaging reduces the uncertainty from spatial and temporal inhomogeneities present in the ground-based datasets; more details can be found in ( $\mathrm{Hu}-$ bert et al., 2017).

The resulting network-averaged drift calculated for the old and new MIPAS data versions versus lidar and ozonesonde data is presented in Fig. 10. Ozonesonde and lidar results are fairly consistent. The MIPAS drift relative to groundbased instruments is not significant for either version. Over the altitude range of $15-37 \mathrm{~km}$, the drift of the old version is $1 \%$ decade $^{-1}$ ( $2 \%$ at the most) more negative or less positive (depending on altitude) than the drift of the new version.
The difference in the drifts between the old and the new versions is not significant because the estimated $2 \sigma$ uncertainty in the drift is at best $2 \%$ decade $^{-1}$ between 20 and $25 \mathrm{~km}$ and larger elsewhere. Hence, the ozonesonde and lidar analyses alone do not allow us to conclude with certainty which data version is more stable. But still, this analysis indicates that it is most likely that the new MIPAS data exhibit a smaller negative drift.

\subsubsection{Drift with respect to Aura MLS}

For calculating drifts with respect to satellite instruments, we have chosen the Aura MLS data as the reference dataset. The reason is that MLS is a dense sampler and it is known to be stable (Hubert et al., 2016). The MIPAS drift estimation with respect to MLS uses profiles matched to $250 \mathrm{~km}$ and $6 \mathrm{~h}$, in the period 2005-2012. The differences between the MIPAS and MLS measurements were taken at every valid altitude grid point of each profile pair; then monthly zonal means of these differences were calculated in $10^{\circ}$ latitude bins. The multi-linear regression model, described in Eckert et al. (2014) and von Clarmann et al. (2010), was then applied to the time series. The resulting drifts are shown in Fig. 11c as a function of altitude and latitude band. Figure 11a shows the same drift estimates for the previous version of MIPAS data. Hatching indicates domains with less than $2 \sigma$ significance.

The comparison of the old (Fig. 11a) and the new (Fig. 11c) version in Fig. 11 reveals the following features. In the new version, there are a lot fewer areas with significant drift. Combined with the fact that drift uncertainties are of a similar size for the old and new versions, we interpret this reduction of significant areas as an improvement: the drifts became smaller in absolute values. As pointed out by Eckert et al. (2014), the old version exhibited mostly negative drifts, going down to -0.33 ppmv decade ${ }^{-1}$ and becoming more negative with altitudes up to $\sim 40 \mathrm{~km}$. This clear pattern of significant negative drifts extended over all latitudes at altitudes over $30 \mathrm{~km}$ and went down to $20 \mathrm{~km}$ at midlatitudes. In the new version, this pattern has disappeared and there is no clear systematic drift pattern; some areas with small positive drifts are neighboring areas with small negative drifts, with the majority of both areas being nonsignificant. This can be attributed to the small absolute values of the drifts. The appearance of some pixels with significant positive drifts is tentatively attributed to an overcorrection in NL coefficients in Level 1B spectra. Version 8 of Level 1B MIPAS spectra, which at the time of this writing is in a testing phase, is expected to correct for this undesirable effect.

In summary, we found out that the ground-based and MLS-based analyses provide consistent results. Both indicate that the drifts of the new version are less negative or more positive nearly everywhere above $15 \mathrm{~km}$. 

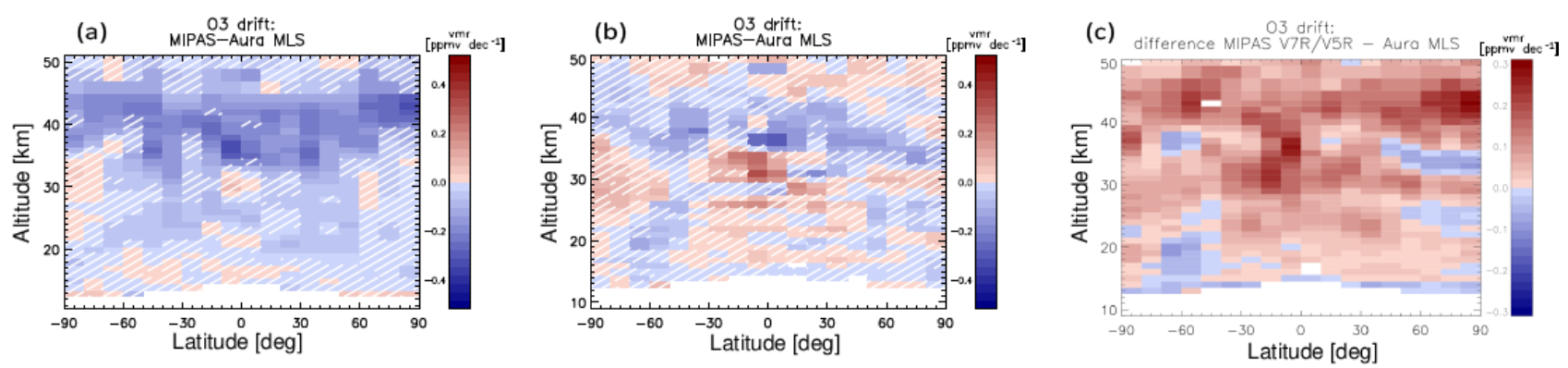

Figure 11. Altitude-latitude cross section of absolute drifts of MIPAS V5R (a) and V7R (b) vs. Aura MLS ozone measurements as well as their difference (c). Hatched areas mean that the significance is less than $2 \sigma$.
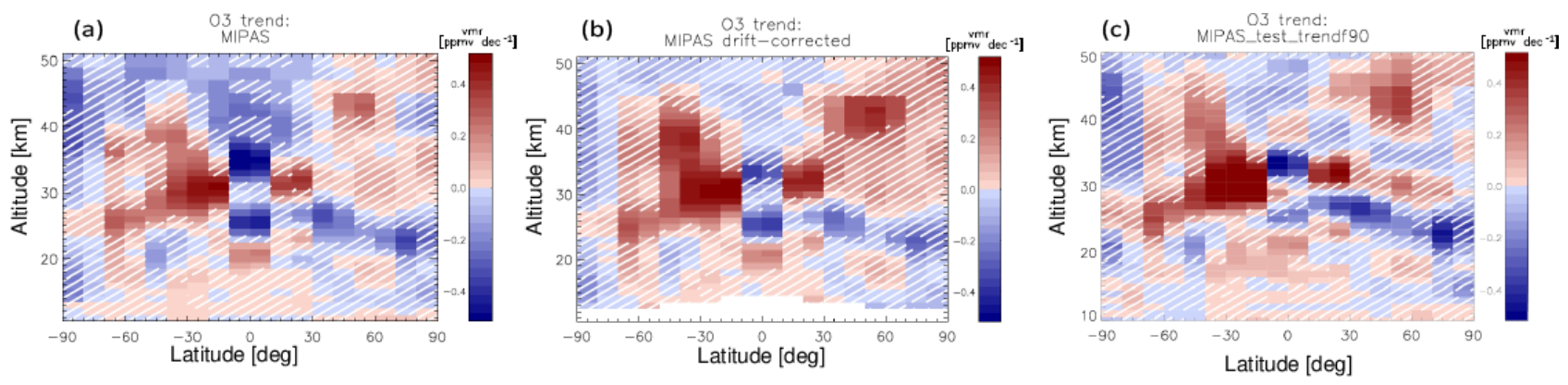

Figure 12. MIPAS 10-year trends calculated based on V5R data without drift correction (a), drift-corrected V5R data (b), and V7R data without drift correction (c). Hatched areas mean that the significance is less than $2 \sigma$.

\section{Update of 10-year trends from MIPAS}

Although 10 years of data provides a time series that is too short to sample the solar cycle, we calculated the newly estimated trends on it in order to compare with similar trends calculated in Eckert et al. (2014). The comparison of 10-year MIPAS trends calculated for old and new datasets is shown in Fig. 12. For convenience of the reader, we reproduce two relevant figures from Eckert et al. (2014) as the left and middle panels in Fig. 12.

One should be aware that trends in Eckert et al. (2014) are already drift-corrected, so we do not expect an improvement of final drift-corrected trend estimates from Eckert et al. (2014). Instead, we expect that the new trends (Fig. 12c) are closer to drift-corrected trends from Eckert's paper (Fig. 12b; this is Fig. 15 from Eckert's paper) than uncorrected original trends were (Fig. 12a; this is Fig. 13 in Eckert et al., 2014). As this expectation is confirmed, we learn that the NL correction is successful and probably also applicable to other species for which no easy drift correction via comparison to external instruments is possible.

A time series of 10 years is arguably too short to estimate a climatologically relevant trend; a longer time series can be constructed by merging the MIPAS ozone record with SAGE II and OMPS ozone records (Laeng et al., 2018).

\section{Conclusions}

We have presented a new retrieval setup for MIPAS $\mathrm{O}_{3}$ retrieval and assessed the long-term stability of the new MIPAS ozone dataset retrieved with the KIT IMK/IAA scientific level 2 MIPAS processor from the new version 7 Level 1B MIPAS spectra. As a sanity check of the new retrieval scheme, we assessed the bias of the old and of the new datasets with respect to two ozonesonde stations, Boulder and Hilo, and two satellite instruments, ACE-FTS and MLS. The biases with respect to the ozonesondes from Hilo and Boulder stations are consistent, with an agreement within $\pm 5 \%$ at $20-30 \mathrm{~km}$. At $12-14 \mathrm{~km}$, the bias against Boulder is reduced by $5 \%$. For the Hilo station, the bias is reduced from $15 \%$ to $5 \%$ from 12 to $20 \mathrm{~km}$. The old and new MIPAS datasets were compared with ACE-FTS and MLS satellite instruments. With respect to ACE-FTS, the new version of the MIPAS ozone dataset shows a bias reduction by about $2 \%$ at $10-20 \mathrm{~km}$, a bias reduction by about $1 \%$ to $4 \%$ at $30-52 \mathrm{~km}$ and a bias reduction by about $6 \%-8 \%$ at $60 \mathrm{~km}$ and higher. With respect to MLS, a bias reduction by $1 \%$ to $12 \%$ is observed in the lower mesosphere (52 $\mathrm{km}$ and higher), while at other heights the bias is slightly increased by $1 \%$ to $4 \%$. Around $35 \mathrm{~km}$, the new version demonstrates an improvement with respect to ACE-FTS, where the bias is reduced from $2 \%$ to almost $0 \%$, and a degradation with respect to MLS, where the bias increases from $3 \%$ for the previous ver- 
sion to $5 \%$ for the new version. In the UTLS, the comparison with ACE-FTS still demonstrates a clear improvement, while MLS agrees better with the old version at $12-14 \mathrm{~km}$ in altitude and better with the new version at 10-12 and $14-16 \mathrm{~km}$ in altitude.

To estimate the drift, the old and the new data were compared to a ground-based network of ozonesonde and lidar stations and to satellite ozone data from the Aura MLS instrument. Obtained MIPAS drifts relative to the ground-based network are not significant for either version. The groundbased network analysis alone does not allow a robust conclusion on whether the old or new version is more stable. In the satellite analysis, the pattern of significant negative drifts at heights over $30 \mathrm{~km}$ and going down to $20 \mathrm{~km}$ at midlatitudes, which was observed in the old version, has completely disappeared in the new version. The appearance of some pixels with significant positive drift in the new version is tentatively attributed to the overcorrection in NL coefficients in Level 1B spectra, which is expected to be corrected in the upcoming version 8 of Level 1B MIPAS spectra. The results of network and satellite drift analysis are consistent: both indicate that the drifts of the new version are less negative or more positive nearly everywhere above $15 \mathrm{~km}$.

The 10-year MIPAS ozone trends calculated from the old and the new data versions were compared. The new trends are closer to old drift-corrected trends than the old uncorrected trends were. From this, we conclude that the NL correction performed on Level $1 \mathrm{~B}$ data is successful and probably also applicable to other species for which no easy drift correction via comparison to external instruments is possible.

Data availability. The data are available at https://www.imk-asf. kit.edu/english/308.php (IMK-ASF - KIT, 2018).

Competing interests. The authors declare that they have no conflict of interest.

Special issue statement. This article is part of the special issue "Quadrennial Ozone Symposium 2016 - Status and trends of atmospheric ozone (ACP/AMT inter-journal SI)". It is a result of the Quadrennial Ozone Symposium 2016, Edinburgh, United Kingdom, 4-9 September 2016.

Acknowledgements. The authors are thankful to the referees for the comments that helped to improve the paper. We also thank Anne Kleinert for helpful comments. This work was performed in the framework of European Space Agency (ESA) project Ozone_cci. All four MIPAS teams acknowledge ESA for providing MIPAS L1b data. The ACE mission is supported primarily by the Canadian Space Agency. Work at the Jet Propulsion Laboratory was performed under contract with the National Aeronautics and Space Administration.
The service charges for this open-access publication have been covered by a Research Centre of the Helmholtz Association. We acknowledge support by the Deutsche Forschungsgemeinschaft and Open Access Publishing Fund of the Karlsruhe Institute of Technology.

The article processing charges for this open-access publication were covered by a Research

Centre of the Helmholtz Association.

Edited by: Sophie Godin-Beekmann

Reviewed by: two anonymous referees

\section{References}

Eckert, E., von Clarmann, T., Kiefer, M., Stiller, G. P., Lossow, S., Glatthor, N., Degenstein, D. A., Froidevaux, L., GodinBeekmann, S., Leblanc, T., McDermid, S., Pastel, M., Steinbrecht, W., Swart, D. P. J., Walker, K. A., and Bernath, P. F.: Drift-corrected trends and periodic variations in MIPAS IMK/IAA ozone measurements, Atmos. Chem. Phys., 14, 2572589, https://doi.org/10.5194/acp-14-2571-2014, 2014.

Flaud, J.-M., Piccolo, C., Carli, B., Perrin, A., Coudert, L. H., Teffo, J. L., and Brown L. R.: Molecular line parameters for the MIPAS (Michelson Interferometer for Passive Atmospheric Sounding) experiment, Atmos. Ocean. Opt., 16, 172-182, 2003.

Froidevaux, L., Jiang, Y. B., Lambert, A., Livesey, N. J., Read, W. G., Waters, J. W., Browell, E. V., Avery, J. W. H. M. A., McGee, T. J., Twigg, L. W., Sumnicht, G. K., Jucks, K. W., Margitan, J. J., Sen, B., Stachnik, R. A., Toon, G. C., Bernath, P. F., Boone, C. D., Walker, K. A., Filipiak, M. J., Harwood, R. S., Fuller, R. A., Manney, G. L., Schwartz, M. J., Daffer, W. H., Drouin, B. J., Cofield, R. E., Cuddy, D. T., Jarnot, R. F., Knosp, B. W., Perun, V. S., Snyder, W. V., Stek, P. C., Thurstans, R. P., and Wagner, P. A.: Validation of Aura Microwave Limb Sounder stratospheric ozone measurements, J. Geophys. Res., 113, D15S20, https://doi.org/10.1029/2007JD008771, 2008.

García-Comas, M., Funke, B., Gardini, A., López-Puertas, M., Jurado-Navarro, A., von Clarmann, T., Stiller, G., Kiefer, M., Boone, C. D., Leblanc, T., Marshall, B. T., Schwartz, M. J., and Sheese, P. E.: MIPAS temperature from the stratosphere to the lower thermosphere: Comparison of vM21 with ACE-FTS, MLS, OSIRIS, SABER, SOFIE and lidar measurements, Atmos. Meas. Tech., 7, 3633-3651, https://doi.org/10.5194/amt-7-36332014, 2014.

Garcia, R. R., Smith, A. K., Kinnison, D. E., de la Cámara, Á, and Murphy, D.: Modifications of the gravity wave parameterization in the Whole Atmosphere Community Climate Model: Motivation and results, J. Geophys. Res.-Atmos., https://doi.org/10.1175/JAS-D-16-0104.1, 2016.

Glatthor, N., von Clarmann, T., Stiller, G. P., Kiefer, M., Laeng, A., Dinelli, B. M., Wetzel, G., and Orphal, J.: Differences in ozone retrieval in MIPAS channels $\mathrm{A}$ and $\mathrm{AB}$ : a spectroscopic issue, Atmos. Meas. Tech. Discuss., https://doi.org/10.5194/amt-201849, in review, 2018.

Haenel, F. J., Stiller, G. P., von Clarmann, T., Funke, B., Eckert, E., Glatthor, N., Grabowski, U., Kellmann, S., Kiefer, M., Lin- 
den, A., and Reddmann, T.: Reassessment of MIPAS age of air trends and variability, Atmos. Chem. Phys., 15, 13161-13176, https://doi.org/10.5194/acp-15-13161-2015, 2015.

Hedin, A. E.: Extension of the MSIS thermosphere model into the middle and lower altmosphere, J. Geophys. Res., 96, 1159-1172, 1991.

Hubert, D., Lambert, J.-C., Verhoelst, T., Granville, J., Keppens, A., Baray, J.-L., Bourassa, A. E., Cortesi, U., Degenstein, D. A., Froidevaux, L., Godin-Beekmann, S., Hoppel, K. W., Johnson, B. J., Kyrölä, E., Leblanc, T., Lichtenberg, G., Marchand, M., McElroy, C. T., Murtagh, D., Nakane, H., Portafaix, T., Querel, R., Russell III, J. M., Salvador, J., Smit, H. G. J., Stebel, K., Steinbrecht, W., Strawbridge, K. B., Stübi, R., Swart, D. P. J., Taha, G., Tarasick, D. W., Thompson, A. M., Urban, J., van Gijsel, J. A. E., Van Malderen, R., von der Gathen, P., Walker, K. A., Wolfram, E., and Zawodny, J. M.: Ground-based assessment of the bias and long-term stability of 14 limb and occultation ozone profile data records, Atmos. Meas. Tech., 9, 2497-2534, https://doi.org/10.5194/amt-9-2497-2016, 2016.

Hubert, D., Lambert, J.-C., Verhoelst, T., and Keppens, A.: II: Search for time-dependences in comparisons of ground-based and limb profile ozone records, Poster on LOTUS Workshop in Paris, 12-13 March, 2017.

Hubert et al.: Quality assessment of the Ozone_cci Climate Research Data Package (release 2017): 3. Ground-based validation of limb ozone profile data products, in preparation, 2018.

IMK-ASF - KIT: MIPAS ENVISAT Data, available at: https: //www.imk-asf.kit.edu/english/308.php, last access: 8 August 2018.

Kiefer, M., Aubertin, G., Birk, M., de Laurentis, M., Eckert, E., Kleinert, A., Perron, G., and Wagner, G.: Impact of Improved Corrections for MIPAS Detector Non-Linearity, Atmospheric Composition Validation and Evolution, Frascati, 13-15 March 2013, Abstract Book, p. 38, 2013.

Kleinert, A., Aubertin, G., Perron, G., Birk, M., Wagner, G., Hase, F., Nett, H., and Poulin, R.: MIPAS Level 1B algorithms overview: operational processing and characterization, Atmos. Chem. Phys., 7, 1395-1406, https://doi.org/10.5194/acp-7-13952007, 2007.

Kurylo, M. and Zander, R.: The NDSC - Its status after ten years of operation, In Proceedings of the Quadrennial Ozone Symposium 2000, Hokkaido Univ., Sapporo, Japan, edited by: NASDA, 167168,2001

Laeng, A., Grabowski, U., von Clarmann, T., Stiller, G., Glatthor, N., Höpfner, M., Kellmann, S., Kiefer, M., Linden, A., Lossow, S., Sofieva, V., Petropavlovskikh, I., Hubert, D., Bathgate, T., Bernath, P., Boone, C. D., Clerbaux, C., Coheur, P., Damadeo, R., Degenstein, D., Frith, S., Froidevaux, L., Gille, J., Hoppel, K., McHugh, M., Kasai, Y., Lumpe, J., Rahpoe, N., Toon, G., Sano, T., Suzuki, M., Tamminen, J., Urban, J., Walker, K., Weber, M., and Zawodny, J.: Validation of MIPAS IMK/IAA V5R_O3_224 ozone profiles, Atmos. Meas. Tech., 7, 39713987, https://doi.org/10.5194/amt-7-3971-2014, 2014.

Laeng, A., Hubert, D., Verhoelst, T., von Clarmann, T., Dinelli, B. M., Dudhia, A., Raspollini, P., Stiller, G., Grabowski, U., Keppens, A., Kiefer, M., Sofieva, V., Froidevaux, L., Walker, K. A., Lambert, J.-C., and Zehner, C.: The Ozone Climate Change Initiative: Comparison of four Level-2 Processors for the Michelson Interferometer for Passive Atmo- spheric Sounding (MIPAS), Remote Sens. Environ., 162, 316343, https://doi.org/10.1016/j.rse.2014.12.013, 2015.

Laeng, A., von Clarmann, T., Stiller, G., Sofieva, V., Kramarova, N., Walker, K. A., Zawodny, J., and Plieninger, J.: Creating longterm climate data records using transfer functions: methodology and application to SAGE II, MIPAS and OMPS ozone profile datasets, in preparation, 2018.

Lambert, J.-C., Van Roozendael, M., De Mazière, M., Simon, P., Pommereau, J.-P., Goutail, F., Sarkissian, A., and Gleason, J.: Investigation of pole-to-pole performances of spaceborne atmospheric chemistry sensors with the NDSC, Atmos. Sci., 56, 176193, 1999.

Levenberg, K.: A method for the solution of certain non-linear problems in least squares, Quart. Appl. Math., 2, 164-168, 1944.

López-Puertas, M., Funke, B., Jurado-Navarro, A. A., GarcíaComas, M., Gardini, A., Boone, C. D., Rezac, L, and Garcia, R.: Validation of the MIPAS $\mathrm{CO}_{2}$ volume mixing ratio in the mesosphere and lower thermosphere and comparison with WACCM simulations, J. Geophys. Res., 122, 1-22, 2017.

López-Puertas, M., García-Comas, M., Funke, B., Gardini, A., Stiller, G. P., von Clarmann, T., Glatthor, N., Laeng, A., Kaufmann, M., Sofieva, V. F., Froidevaux, L., Walker, K. A., and Shiotani, M.: MIPAS observations of ozone in the middle atmosphere, Atmos. Meas. Tech., 11, 2187-2212, https://doi.org/10.5194/amt-11-2187-2018, 2018.

Marquardt, D. W.: An algorithm for least-squares estimation of nonlinear parameters, J. Soc. Indust. Appl. Math., 11, 431-441, 1963.

Marsh, D. R.: Chemical-dynamical coupling in the Mesosphere and Lower Thermosphere, Aeronomy of the Earth's Atmosphere and Ionosphere, IAGA Special Sopron Book Ser., vol. 2, edited by: Abdu, M., Pancheva, D., and Bhattacharyya, A., 1st ed., 370 pp., ISBN: 978-94-007-0325-4, Springer, Dordrecht, 2011.

Marsh, D. R., Mills, M. J., Kinnison, D. E., Lamarque, J.F., Calvo, N., and Polvani, L. M.: Climate change from 1850 to 2005 simulated in CESM1(WACCM), J. Climate, 26, https://doi.org/10.1175/JCLI-D-12-00558.1, 2013.

Neely III, R. R., English, J. M., Toon, O. B., Solomon, S., Mills, M., and Thayer, J. P.: Implications of extinction due to meteoritic smoke in the upper stratosphere, Geophys. Res. Lett., 38, https://doi.org/10.1029/2011GL049865, 2011.

Plieninger, J., von Clarmann, T., Stiller, G. P., Grabowski, U., Glatthor, N., Kellmann, S., Linden, A., Haenel, F., Kiefer, M., Höpfner, M., Laeng, A., and Lossow, S.: Methane and nitrous oxide retrievals from MIPAS-ENVISAT, Atmos. Meas. Tech., 8, 4657-4670, https://doi.org/10.5194/amt-8-4657-2015, 2015.

Sofieva, V. F., Rahpoe, N., Tamminen, J., Kyrölä, E., Kalakoski, N., Weber, M., Rozanov, A., von Savigny, C., Laeng, A., von Clarmann, T., Stiller, G., Lossow, S., Degenstein, D., Bourassa, A., Adams, C., Roth, C., Lloyd, N., Bernath, P., Hargreaves, R. J., Urban, J., Murtagh, D., Hauchecorne, A., Dalaudier, F., van Roozendael, M., Kalb, N., and Zehner, C.: Harmonized dataset of ozone profiles from satellite limb and occultation measurements, Earth Syst. Sci. Data, 5, 349-363, https://doi.org/10.5194/essd5-349-2013, 2013.

Sofieva, V. F., Kyrölä, E., Laine, M., Tamminen, J., Degenstein, D., Bourassa, A., Roth, C., Zawada, D., Weber, M., Rozanov, A., Rahpoe, N., Stiller, G., Laeng, A., von Clarmann, T., Walker, K. A., Sheese, P., Hubert, D., van Roozendael, M., Zehner, C., 
Damadeo, R., Zawodny, J., Kramarova, N., and Bhartia, P. K.: Merged SAGE II, Ozone_cci and OMPS ozone profile dataset and evaluation of ozone trends in the stratosphere, Atmos. Chem. Phys., 17, 12533-12552, https://doi.org/10.5194/acp-17-125332017, 2017.

Stiller, G. P. (Ed.): The Karlsruhe Optimized and Precise Radiative Transfer Algorithm (KOPRA), Wiss. Ber. FZKA 6487, Forschungszentrum, Karlsruhe, Germany, 2000.

Thompson, A. M., Miller, S. K., Tilmes, S., Kollonige, D. W., Witte, J. C., Oltmans, S. J., Johnson, B. J., Fujiwara, M., Schmidlin, F. J., Coetzee, G. J. R., Komala N., Maata, M., Maznorizan bt Mohamad, Nguyo, J., Mutai, C., Ogino, S.Y., Raimundo Da Silva, F., Paes Leme, N. M., Posny, F., Scheele, R., Selkirk, H. B., Shiotani, M., Stübi, R., Levrat, G., Calpini, B., Thouret, V., Tsuruta, H., Canossa, J. V., Vömel, H., Yonemura, S., Diaz, J. A., Tan Thanh, N. T., and Thuy Ha, H. T.: Southern Hemisphere Additional Ozonesondes (SHADOZ) ozone climatology (2005-2009): Tropospheric and tropical tropopause layer (TTL) profiles with comparisons to OMI-based ozone products, J. Geophys. Res., 117, D23301, https://doi.org/10.1029/2011JD016911, 2012.

von Clarmann, T., Glatthor, N., Grabowski, U., Höpfner, M., Kellmann, S., Kiefer, M., Linden, A., Mengistu Tsidu, G., Milz, M., Steck, T., Stiller, G. P., Wang, D. Y., Fischer, H., Funke, B., Gil-López, S., and López-Puertas, M.: Retrieval of temperature and tangent altitude pointing from limb emission spectra recorded from space by the Michelson Interferometer for Passive Atmospheric Sounding (MIPAS), J. Geophys. Res., 108, 4736, https://doi.org/10.1029/2003JD003602, 2003. von Clarmann, T., Höpfner, M., Kellmann, S., Linden, A., Chauhan, S., Funke, B., Grabowski, U., Glatthor, N., Kiefer, M., Schieferdecker, T., Stiller, G. P., and Versick, S.: Retrieval of temperature, $\mathrm{H}_{2} \mathrm{O}, \mathrm{O}_{3}, \mathrm{HNO}_{3}, \mathrm{CH}_{4}, \mathrm{~N}_{2} \mathrm{O}, \mathrm{ClONO}_{2}$ and $\mathrm{ClO}$ from MIPAS reduced resolution nominal mode limb emission measurements, Atmos. Meas. Tech., 2, 159-175, https://doi.org/10.5194/amt-2159-2009, 2009.

von Clarmann, T., Stiller, G., Grabowski, U., Eckert, E., and Orphal, J.: Technical Note: Trend estimation from irregularly sampled, correlated data, Atmos. Chem. Phys., 10, 6737-6747, https://doi.org/10.5194/acp-10-6737-2010, 2010.

Wagner, G. and Birk, M.: Improvement of DLR detector nonlinearity characterization for MIPAS/Envisat, Support to MIPAS Phase E activities Technical Note, issue 1A, 29 June 2005. 